CASE REPORT

\title{
Combination of Low Dose Ketamine, Paracetamol, and Tramadol for Opioid Induces Hyperalgesia in Lung Cancer with Intra Abdominal Metastases
}

\author{
Boyke Marthin Simbolon $^{\bowtie}$, Mual Kristian Sinaga \\ Department of Anaesthesiology, Intensive Care and Pain Management/ Siloam Dhirga Surya \\ Hospital, Medan, Indonesia \\ ${ }^{\square}$ Korespondensi: boykemarthins@yahoo.com
}

\begin{abstract}
Background: Opioid induced hyperalgesia or $\mathrm{OIH}$ is one of exaggerated response to pain secondary to using of the opioid itself. High dosage of opioid in long term (days to weeks) relate to increased $\mathrm{OIH}$ occurrence.

Case: Female, 58 yrs, BMI 17.77, complained severe abdominal pain with NRS 8/10. Patient suffered from lung cancer stage 3 with intra abdominal metastases. Previously patient had received analgesic paracetamol $1 \mathrm{gr}$ TID, dexketoprofen 25mg TID, parecoxib 40mg OD, morphine 10mg BD and fentanyl patch $50 \mu \mathrm{g}$. Then fentanyl was given $25 \mu \mathrm{g}$ IV twice with interval of 15 minutes. Patient still complained for pain and eventually pain severity increased to NRS 10/10. Afterwards patient was given low dose ketamin $0.1 \mathrm{mg} / \mathrm{kg}$ slow IV push, paracetamol $1 \mathrm{gr}$ IV, and tramadol 50mg IV. After 15 minutes observation, pain decreased to NRS 5/10.

Discussion: Decreasing total dose of opioid consumed may decresed OIH. It may be performed by improving analgesia by using combination of analgesic and intervention strategy.

Conclusion: combination of low dose ketamine $(0.1 \mathrm{mg} / \mathrm{kg})$, paracetamol, and tramadol may be benefit for patient with opioid induces hyperalgesia in lung cancer stage 3 with intra abdominal metastases.
\end{abstract}

Keywords: abdominal metastases; abdominal pain; low dose ketamine; numeric rating scale; opioid induced hyperalgesia 


\section{INTRODUCTION}

Opiod is recently, significantly and frequently used in chronic cancer and non cancer pain treatment. Using long term opioid may lead to some problems. First, no upportive evidence for its effectiveness in long term treatment, second: it is known well for possibility of misuse opiod and opioid is related to unwanted event including hyperalgesia (opioid induced hyperalgesia or $\mathrm{OIH}$ ).

Hyperalgesia is defined as increasing pain response to stimulus that causing pain. ${ }^{1} \mathrm{OIH}$ is sensitivity to nociceptive receptor secondary to opiod. Initially in $\mathrm{OIH}$ opioid will treat the pain, but eventually patient become more sensitive to pain stimulus. In other words, in adding analgesic effect, opioid produce opposite effect of pain stimulus. OIH patient probably experience pain that might be similar to pain in patient using opiod or other thype of pain. Tolerance is defined as decreasing response on medicine progressively, so additional dosage will be needed to achieve desireable analgesic effect. Increasing dosage of medicine will not overcome $\mathrm{OIH}$.

$\mathrm{OIH}$ is one of exaggerated response to pain secondary to using of the opioid itself. Tappering the dose or discontinuing the opiod may decrease $\mathrm{OIH}$, while increasing the dose may increase $\mathrm{OIH}$. OIH is reversible, but it will take long time to get free from the opioid. ${ }^{2}$ Using high dosage of opioid in long term (days to weeks) relate to increased OIH occurence, but in few case short term treatment may generate some effects. ${ }^{3,4}$ For example, after initial use, analgesic effect will be seen in 1-5 hours, followed by decreased treshold pain and last in few hours or days. ${ }^{3}$ Therefore using in short or long term may generate $\mathrm{OIH}$.
OIH secondary to high dose of morphine (opioid) is mediated by 2 non-opioid receptor, glycin and NMDA receptor in spinal cord. This was proven by the evidence that opioid antagonist does not affect OIH secondary to high dose opioid. $^{4}$

\section{CASE}

A female, 58 years old, BMI 17,77 complained of severe abdominal pain with NRS 8/10. Patient suffered from lung cancer stage 3 with abdominal metastases. Previously patient took paracetamol 1gr TID, dexketoprofen $25 \mathrm{mg}$ TID, parecoxib 40mg OD,morphine 10mg BD and fentanyl patch $50 \mu \mathrm{g}$.

Subsequently fentanyl $25 \mu \mathrm{g}$ IV was given twice with interval 15 minutes. Patient still complained of abdominal pain, and eventually increased pain to NRS 10/10. Then low dose ketamine $0.1 \mu \mathrm{g} / \mathrm{kg}$ slow IV bolus, paracetamol $1 \mathrm{gr}$ $\mathrm{IV}$, and tramadol 50mg IV were given. After 15minutes patient experienced decreased pain to NRS 5/10. Furthermore, ketamine $0.1 \mu \mathrm{g} / \mathrm{kg} /$ hour was continued and metoclopramide $10 \mathrm{mg}$ TID were added. On our observation, NRS maintain in NRS 4$5 / 10$. Patient refused for invasive treatment and decided to continue palliative care. Patient experienced minimal pain and eventually died after 4 days.

\section{DISCUSSION}

\section{Mechanism of OIH}

The exact mechanism of $\mathrm{OIH}$ has not been defined yet. But there are 2 mechanism in $\mathrm{OIH}$, which are central mechanism, such as NMDA receptor activation, spinal dinorphin, descending facilitation, decreased reuptake, 
enhanced nociceptive respond, and other mechanism.

\section{Central Mechanism}

NMDA receptor activation

NMDA receptor play important role in pain signal. Some opioid and its metabolite have agonist effect on NMDA receptor in spinal cord. As opioid activate NMDA receptor, it generate influx of calsium which increase excitability of the neuron. The increased neuron excitability will facilitate transmission of pain impulse which caused by every pain stimulus. In this event, influx of calsium that activate PKC (protein kinase C) is generated by fosforilation and opioid receptor activation. In addition, influx of calsium activate NO synthesis in neuron which decrease opiod effect such as morphine. ${ }^{5-}$ 9

\section{Spinal Dinorphin}

Spinal dinorphin is endogenous opioid which mostly active in kappa receptor of opioid and bind to NMDA receptor. ${ }^{10}$ Spinal dinorphin level was seen increased in continous infusion of opioid, such as morphine. Increased spinal dinorphin lead to neuropeptide spinal excitatory such as Calcitonin Gene Related Peptide (CGRP) of primary afferent on spinal cord. ${ }^{11}$ Increased release neuropeptide excitatory after pain stimulus will generate $\mathrm{OIH} .{ }^{12}$ Therefore analgesic effect of morphine can be relieved by blocking spinal dinorphin effect using antiserum of dinorphin. ${ }^{10}$

\section{Descending Facilitiation}

Rostral Ventromedial Medulla (RVM) is one of descending pathway, on which modulation transmission and pain stimulation on dorsal horn level of spinal cord occur. RVM has 3 different types of neuron: on cell, off cell, and neutral cell, of which each of them has effect to increase, inhibit or none on nociceptive process in dorsal horn of spinal cord. ${ }^{13}$

Morphine given in sufficient dosage generate analgesia due to activation of off cell and inhibition of on cell. ${ }^{14}$ This process was observed in a study on rats who exposed to long term morphine and eventually experienced increased pain sensation by increasing sensation of on cell to pain stimulus. This study probably managed to explain how OIH occur. ${ }^{15} \mathrm{~A}$ lesion on dorsolateral funiculus (the brain part who facilitate descending pathway from RVM to dorsal horn) may prevent or relieve OIH. ${ }^{16}$

\section{Decrease Reuptake and Enhaced Nociceptive Respond \\ Decreasing reuptake of nociceptive neurotransmitter such as substance $\mathrm{P}$ and glutamate of affrent nerve on spinal cord and increasing response of neurotransmiter on spinal cord after long term opiod may generate $\mathrm{OIH} .{ }^{17}$}

\section{Other Mechanism}

Inhibiton of important transport system such as P-glycoprotein of which part of secretion of toxin, including morphine and its metabolite released from cerebro spinal fluid, may play role in initiating, maintain and aggravate $\mathrm{OIH}^{3}$ This transport system was inhibited by medication such as verapamil, cyclosporin, ketokonazole and quinin and result in high morphine level and its metabolite in CSF. ${ }^{18}$

In clinical studies, $\mathrm{OIH}$ had ben observed in patient given high opiod dose, but not in patient given low and medium dose. Many studies explained that in cases where high opioid dose increased fast (intrathecally), opiod metabolites (such as 3-glucoronic morphine) cause neuroexcitation and induced hyperalgesia, where many patients were 
reported with increased pain on pain site. ${ }^{19-21}$

\section{Diagnosing OIH}

OIH typically was perceived as difused pain and according to distribution pattern. The new pain expand out of intial pain site. Different to tolerance, OIH become severe in high opioid dose. Increased pain is secondary to decreased effective dose and occur relatively slow, while increased pain in OIH occur rapidly and with strong intensity compared to initial pain. ${ }^{22}$

In this case patient experienced hyperalgesia secondary to opioid of which opioid (fentanyl and morphine) had been given for almost 2 weeks. Patient suffered from chronic pain secondary to lung cancer with intraabdominal metastases which suggested patient to consume opioid analgesic in long term. But this long term opioid led to a condition named hyperalgesia. Hyperalgesia is increased pain response to stimulus that usually causing pain.

In $\mathrm{OIH}$, there is an increasing sensitivity of nociceptive receptor secondary to opioid use. In this case patient suffered from severe pain, however the pain was not relieved after fentanyl $(2.5 \mu \mathrm{g} / \mathrm{kg})$ given, furthermore the pain tended to be more severe after fentanyl given.

\section{Strategy to Minimize OIH}

Decreasing total dose of opioid consumed may decresed OIH. It may be performed by improving analgesia by using combination of analgesic and intervention strategy. ${ }^{23}$

\section{Pharmacotherapy}

This strategy might be performed by combining anticonvulsant, non steroid anti imflammatory drugs (NSAID) as well as to treat patient with neuropathy or nociceptive pain.

\section{Intervention Therapy}

Intervention therapy may block nociceptive input and give 2 function, which are helping diagnosing etilogy of pain and give benefit of therapy. Regional block, peripheral nerve block, spinal cord stimulation or combination of oral analgesic may be considered as alternative strategy on chronic pain treatment.

Additional alternative treatment suggested in this case is epidural analgesic, of which it will increase nociceptive input, hence decrease NRS as well. However patient did not consent for it.

\section{Psychological Therapy}

Studies have explained that cognitive behavioral therapy may become an effective treatment strategy in chronic pain condition. By phsychological intervention, pain and disabilities may improved and opioid dose is lessen.

\section{Strategy to Manage OIH Symptoms}

Improtant aspect in managing $\mathrm{OIH}$ is confirming the diagnosis. Initial step to consider is increased opioid dose and for efficacy evaluation. If pain decreased by increasing the dose, opioid tolerance will be suspected. On contrary, when pain increased, OIH will be suspected. ${ }^{23}$

\section{Decreasing Opiod Dose}

Decreasing opiod dose will relieve hyperalgesia and pain scale. A benefit strategy was reported on decreasing 40$50 \%$ dose and replacing low dose opiod agonist, such as methadone.

\section{Rotation or Shifting Opioid}

Shifting new opioid may regain analgesic efficacy of opioid in patient with tolerance in one type of opioid. 
The equivalent dose table of analgesic opioid may be helpful for calculating the dosage of which will give analgesic dose almost similar in potency and bioavailability. When shifting an opioid to another one, it is advised to decrease new opiod dose $25-50 \%$ for calculating incomplete cross-tolerance. New opioid dose can be titrated gradually when pain increase or become inadequate.

Generally the medicined used are fentanyl, methadone, and buprenorphin.

\section{Fentanyl}

With rotation of opioid from derivative phenanterin such as morphine to piperidin derivate, fentanyl might help some patient with tolerance. Psychochemistry of fentanyl make this medicine ideally given via transdermal. This medicine has low molecule weight, high solubility in lipid, high potency in optimal skin absorbtion.

\section{Buprenorphin}

Buprenorphin might become alternative choice because it is high solubility in lipid and its unique effect as agonist partial on $\mu$-receptor and antagonist on $\mathrm{k}$ receptor. Buprenorphin might be effective to treat $\mathrm{OIH}$, where it inhibit spinal effect of dinorphin (knwon as kreceptor agonist) that will be increased while on opioid given. This medicine is available in transdermal patch or sublingual form.

\section{Methadone}

One of low potent NMDA antagonist, hence it will decrease OIH secondary to high opioid dose. Methadone is used in opioid rotation process to decrease severe effect of improper using of opioid. Rotation of opioid to methadone probably help to decrease $\mathrm{OIH}$ by its ability as NMDA receptor agonist and inhibit norepinephrin and serotonin reuptake. Other benefit of this medicine including cross-tolerance with opioid receptor, relatively long half time (24-36 hours), few variation in plasma level compared to short acting opioid. The limitation of this medicine is drug interaction more often occur compared to other long acting opioid and shifting an opioid to methadone is complex and need experience.

\section{Antagonist NMDA receptor Ketamin}

It is s non competitive antagonist NMDA receptor. There were some evidences based on clinical studies where using low dose ketamine perioperative (pre, intra, and post operative) may decrease hyperalgesia on the wound during post operative periode after opioid intraoperative was given.

Ketamin is available as racemic or as $\mathrm{S}$ ketamin isomer. In a evidence based review of ketamin for chronic pain management, Hocking and Michael suggested IV or subcutaneous ketamin dose ranging 0.125-0.3 mg per hour. ${ }^{24}$ Ketamin has short analgesic effect and need observation during its infusion, therefore it is considered to give orally in patient response to this intervention. Recommended oral dose is started wtih initial dose $0.5 \mathrm{mg} / \mathrm{kg}$ racemic or 0.25 $\mathrm{mg} / \mathrm{kg}$ S-ketamin then evaluate for its analgesic response and duration of action. The subsequent dose may be increased gradually $0.5-0.25 \mathrm{mg} / \mathrm{kg}$ depend on its response and side effects. The average effective dose in the literature is $200 \mathrm{mg}$ a day.

In this case, eventually after giving low dose ketamine $(0.1 \mathrm{mg} / \mathrm{kg})$ pain decreased about $50 \%$. Ketamine given to this patient relieved $\mathrm{OIH}$, which ketamine is as NMDA receptor. Many studies had performed long term opioid 
(few days to weeks) will activate NMDA receptor. When NMDA receptor is activated, it will generate influx of calcium and subsequently increase neuron excitability and produce hyperalgesia.

To increase analgesic effect, other analgesic paracetamol and tramadol were added. Paracetamol is known to have important role, especially inhibition on descendant serotogenic and Prostaglandin H2 Synthase (PGHS). While tramadol as central analgesic with moderate affinity to receptor $\mu$ and low affinity to kappa and delta receptor role as descending spinal inhibition as well by decreasing reuptake of norepinephrine and serotonin.

\section{Dextromethorphan}

It is a non competitive NMDA antagonist. It can influence peripheral pain transmission on spinal NMDA receptor. There were some studies explained the ability of dextrometorphan suppresed $\mathrm{OIH}$, but clinically not significant.

\section{CONCLUSION}

$\mathrm{OIH}$ is one of side effect which the mechanism was unknown well secondary to long term opioid use. Nowadays $\mathrm{OIH}$ event increase when opioid increase used for chronic pain condition. In the case failed with opioid therapy, OIH should be considered as differential diagnosis. Before treating patient with opioid, informed consent should be obtained.

In this case, combination of low dose ketamine, paracetamol, and tramadol might relieve hyperalgesia and decrease NRS to $50 \%$ compared to initial NRS and sustained for about 2 days.

\section{REFERENCES}

1. Jensen TS, Finnerup NB. Allodynia and hyperalgesia in neuropathic pain: clinical manifestations and mechanisms. Lancet Neural. 2014; 13:924-935

2. DuPen A, Shen D, Ersek M. Mechanisms of opioid-induced tolerance and hyperalgesia. Pain Manag Nurs. 2007;8: 113-121

3. Angst MS, Clarck JD. Opioidinduced hyperalgesia: a qualitative systematic review. Anesthesiology. 2006; 104: 570-587

4. Chu LF, Angst MS, Clark D. Opioid-induced hypergesia in humans: molecular mechanisms and clinical considerations. Clin J Pain. 2008; 24: 479-496

5. Elliot K, Minami N, Kolesnikov YA, Pastemak GW, Inturrisi CE. The NMDA receptor antagonists, LY274614 and MK-801, and the nitric oxide synthase inhibitor, NGnitro-L-arginine, attenuate analgesic tolerance to the $\mu$-opiod morphine but not to kappa opioids. Pain. 1994; $56,69-75$

6. Kolesnikov YA, Pick CG, Ciszewska G, Pasternak GW. Blockade of tolerance to morphinee but not to kappa opioids by a nitric oxide synthase inhibitor. Proc Nalt Acad Sci U S A. 1993; 90: 51625166

7. Majeed NH, Przewlocka B, Machelska H, Przewlocki R. Inhibition of nitric oxide synthase attenuates the development of morphinee tolerance and dependence in mice. Neuropharmacology. 1994; 33: 189192

8. Przewlocki R, Machelska $\mathrm{H}$, Przewlocka B. inhibition of nitric oxide synthase enhances morphinee antinocicepption in the rat spinal sord. Life Sci. 1993; 53:PL1-5 
9. Mao J, Price DD, Zhu J, Lu J, Mayer DJ. The inhibition of nitric oxideactivated poly(ADP-ribose) synthetase attenuates trans synaptic alteration of spinal cord dorsal horn neurons and neuropathic pain in the rat. Pain. 1997; 72: 355-366

10. Vanderrah TW, Gardell LR, Burgess SE, Ibrahim $M$, Dogrul A. Dynorphin promotes abnormal pain and spinal opioid anti nociceptive tolerance,. J Neurosci. 2000; 20: 7074-7079

11. Gardell LR. Sustained morphinee exposure induces a spinal dynorphin-dependent enhancement of excitatory transmitter release from primary afferent fibers. J. Neurosci. 2002; 22:6747-6755

12. Mao J, Price DD, Mayer DJ. Mechanisms of hyperalgesia and morphinee tolerance: a current view of their possible interactions. Pain. 1995; 62: 259-274

13. Morgan MM, Heinricher MM, Fields HL. Circuitry linking opioidsensitive nociceptive modulatory systems in periaqueductal gray and spinal cord with rostral ventromedial medulla. Neuroscience. 1992; 47, 863-867

14. Heinricher MM, Morgan MM, Tortorici V, Fields HL. Disinhibition off-cells and antinociception produced by an opioid action within the rostral ventromedial medulla. Neuroscience. 1994; 63: 279-288

15. Meng ID, Harasawa I. Chronic morphinee exposure increase the proportion of on-cells in the rostral ventromedial medulla in rats. Life Sci. 2007; 80: 1915-1920

16. Vanderah,TW. tonic descending from the rostral ventromedial medulla mediates opioid-induced abnormal pain and antinociception tolerance. J Neurosci. 2001; 21, 279286

17. Li X, Clarck JD. Hyperalgesia during opioid abstinence: mediation by glutamate and substance $p$. Anesth Analg. 2002; 95: 979-984, table of contents

18. Lee M, Silverman SM, Hansen H, Patel VB, Manchikanti L. A comprehensive review of opioidinduced hyperalgesia. Pain Physician. 2011; 14:145-161

19. Hemstapat K, Monteith GR, Smith D, Smith MT. Morphinee-3glucuronide's neuro-excitatory effect are mediated via indirect activation of $\mathrm{N}$-methyl-Daspartic acid receptors: mechanistic studies in embryonic cultured hippocampal neurons. Anesth. Analg. 2003; 97: 494-505

20. Smith MT. Neuroexitatory effects of morphinee: evidence implicating the 3-glucuronide metabolites. Clin Exp Pharmachol Physiol. 2000; 27: 524528

21. Wright AW, Mather LE, Smith MT. Hydromorphone-3-glucoronide: a more potent neuro-excitant than its structural analogue, morphinee-3glucoronide. Life Sci. 2001; 69: 409-420

22. Raffa RB, Pergolizzi Jr JV. Opioidinduced hyperalgesia: is it clinically relevant for the treatment of pain patients? Pain Manag Nurs. 2013; 14: e67-83.

23. Velayudhan A, Bellingham G, Forster MP. Opioid - induced hyperalgesia. Continiung Education in Anaesthesia, Critical Care \& Pain. 2014; 14 : 125-129

24. Hocking G, Cousins MJ. Ketamine in chronic pain management: an evidence-based review. Anesth Analg. 2003; 97:1730-9 